\title{
Building Virtual Communities and Virtual Teams of Science teachers - the case of Telmae
}

\author{
Zdena Lustigova \\ Charles University, Faculty of Mathematics and Physics, \\ Laboratory of Online Learning, \\ Prague, V Holesovickach 4, \\ CZ-180 00 Praha 8, Czech Republic \\ lustigo@plk.mff.cuni.cz
}

\section{Summary}

As an example of national and international effort on this field, and concrete model of solution, the author presents TELMAE Virtual Community Environment (VCE) and Learning Object Repository (LOR), developed at Faculty of Mathematics and Physics, Charles University in Prague, for interactive online support of science education and educators. The virtual community of teachers was built mainly within the frame of "State Information Policy in Education Program" (2002-2005) when app. 500 physic teachers participated, and within "New Ways to Science Education" project (2006-2008, app. 350 participants ).

In the meaning time Telmae LOR and virtual learning environment serves to large number of in-service teachers (physics, science) as both, formal and informal, supportive environment for their professional development.

The Telmae virtual learning environment and community space (http://telmae.eu) consists of (1) gateway to Telmae online courses and other online interactive educational sources, (2) learning object repository LOR EDUPORT and (3) SCORM based "unified gateway" to the large variety of learning objects at all Czech universities, participating in the project. The learning environment is surrounded by (4) virtual community of active subscribers and consultants, discussion forums and special interest groups, easy accessible by synchronous and asynchronous communications tools. We also offer (5) special consultancy services, called "Active teachers' online support" (ATOS) and (6) interactive environment, including remote and virtual laboratories, for physics teachers (Telmae Remote and Open Laboratory - ROL). 
As part of the development we are constantly evaluating it and are including users feedback into its improvements. Generally, users' responses are positive and are improving over the years as the technology becomes more available and the teachers get more experienced in using it. Although students are quite often aware of the limitations of the remote access to learning resources like remote labs and online courses they also value their advantages in case of Telmae:1/ validity, 2/ reliability 3/easy access, 4/ simple and comfortable operating and control and 5/readiness for school practice. From social and psychological point of view they appreciate mostly virtual consultancy support and the potential for building virtual teams (to lose the feeling of the "loneliness in the cyber space").

The key advantages and limitations of this solution for the support of interdisciplinary approach to science education, team work, problem and inquiry based learning activities, and the real benefit for virtual learning community of teachers, arising from the creative background of Telmae supportive learning environment, are discussed in many research studies, authors and developers published in last 5 years. 